\title{
SISTEM INFORMASI PEGAWAI BERBASIS WEB PADA KANTOR CAMAT GAUNG ANAK SERKA
}

\author{
Tata Sutama \\ Program Studi Sistem Informasi, Fakultas Teknik dan Ilmu Komputer \\ Universitas Islam Indragiri (UNISI) \\ JI. Provinsi No. 01 Tembilahan Hulu, Indragiri Hilir, Riau - Indonesia \\ Email: tatasutama92@yahoo.com
}

\begin{abstract}
Kantor Camat Gaung Anak Serrka memiliki 27 orang pegawai Pns dan 9 orang pegawai honorer. Pengolahan data pegawai pada Kantor Camat Gaung Anak Serka masih menggunakan microsoft word dan excel yang masih kurang efisien dalam pengolahan data pegawai di mana proses penyimpanan data pegawai masih mengguanakn arsip yang mempersulit dalam proses pencarian data dan pengolahan data pegawai. Maka penulis memutuskan untuk membuat suatu Sistem informasi dengan judul: "Sistem Informasi Pegawai Pada Kantor Camat Gaung Anak Serka Berbasis web. Perancangan sistem informasi pegawai ini akan dirancang menggunakan Macro Media Dremweaver dan Microsoft SQL Server.
\end{abstract}

Kata Kunci: SIMPEG, WEB, Gaung Anak Serka

\section{PENDAHULUAN}

Kantor Camat Gaung Anak Serrka memiliki 27 orang pegawai Pns dan 9 orang pegawai honorer. Pengolahan data pegawai pada Kantor Camat Gaung Anak Serka masih menggunakan microsoft word dan excel yang masih kurang efisien dalam pengolahan data pegawai di mana proses penyimpanan data pegawai masih mengguanakn arsip yang mempersulit dalam proses pencarian data dan pengolahan data pegawai. Maka penulis memutuskan untuk membuat suatu Sistem informasi dengan judul: "Sistem Informasi Pegawai Pada Kantor Camat Gaung Anak Serka Berbasis web. Perancangan sistem informasi pegawai ini akan dirancang menggunakan Macro Media Dremweaver dan Microsoft SQL Server .

\section{TINJAUAN PUSTAKA}

Sistem adalah kumpulan dari elemen-elemen yang berinteraksi untuk mencapai suatu tujuan tertentu. Suatu sistem mempunyai maksud tertentu, ada yang menyebutkan maksud dari suatu sistem adalah untuk mencapai suatu tujuan (goal) dan ada yang menyebutkan untuk mencapai suatu sasaran (objectives). Goal biasanya dihubungkan dengan ruang lingkup yang lebih luas. (Jogiyanto, 2005)

Informasi adalah data data merupakan bebtuk jamak dari bentuk datum atau data-item data adalah kenyataan yang menggambarkan kejadian kejadian dan kesatuan nyata (Jogiyanto 2005).

Pengembangan sistem (system development) dapat berarti menyusun suatu sistem yang baru untuk menggantikan sistem yang lama secara keseluruhan atau memperbaiki sistem yang telah ada. (Jogiyanto, 2005)

Pengembang sistem dapat berarti menyusun sistem yang baru untuk menggantikan sistem yang lama secara keseluruhan atau memperbaiki sistem yang telah ada. Sistem yang lama perlu diperbaiki karena adanya permasalahan-permasalahan yang timbul di sistem yang lama. (Jogiyanto, 2005)

Metode ini merupakan metode yang sering digunakan oleh penganalisa sistem pada umumnya. Inti dari metode waterfall adalah pengerjaan dari suatu sistem dilakukan secara berurutan atau secara linear. Jadi jika langkah satu belum dikerjakan maka tidak akan bisa melakukan pengerjaan langkah 2, 3 dan seterusnya. Secara otomatis tahapan ke-3 akan bisa dilakukan jika tahap ke-1 dan ke-2 sudah dilakukan. 
Metode analisis merupakan metode penulisan ilmiah yang dilakukan dengan cara menggabung antara metode kepustakaan dan metode wawancara. Sumber penulisan diambil dari literatur-literatur kepustakaan dan dari hasil wawancara para narasumber. Metode analisis ialah cara penanyanan terhadap sesuatu obyek ilmiah tertentu dengan jalan memilah-milahkan antara pengertian yang satu dengan pengertian-pengertian yang lainnya untuk sekedar memperoleh kejelasan mengenai halnya. Jadi dalam hal ini orang tidak akan memperoleh sesuatu pengetahuan yang sifatnya baru sama sekali. Penerapan metode analisis ini dapat dilakukan terhadap pengertian pengertian yang bersifat apriori dan juga dapat dilakukan terhadap pengertian-pengertian yang bersifat aposteriori.

\section{PERANCANGAN SISTEM}

Diagram konteks digunakan untuk menggambarkan system pengolahan data pegawai secara garis besar atau keseluruhan. Diagram konteks ini dirancang memperhatikan masukan yang dibutuhkan oleh system dan keluaran yang dihasilkan oleh system. Diagram konteks system pengolahan data pegawai digambarkan sebagai berikut :

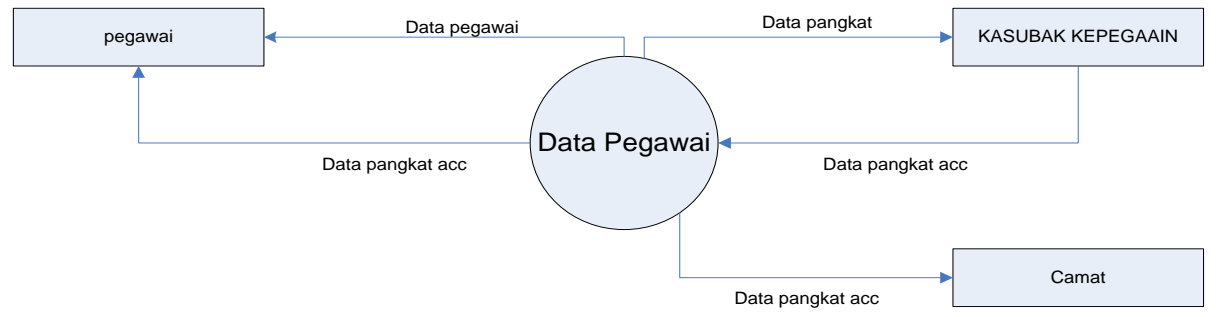

\section{Gambar 1 Diagram Konteks Yang Sedang Berjalan}

Data Flow Diagram pada level 1 menampilkan 11 buah proses utama yaitu input data pegawai, input data cuti, input data pensiun, input data kenaikan pangkat, cetak data pegawai, cetak data cuti, cetak data pensiun, cetak data kenaikan pangkat, acc laporan cuti, acc laporan pensiun, dan acc laporan kenaikan pangkat. Aliran-aliran data menghubungkan antara satu proses dengan proses lainnya, antara entity dengan proses, antara proses dengan file penyimpanan data, dan file penyimpanan data dengan proses.

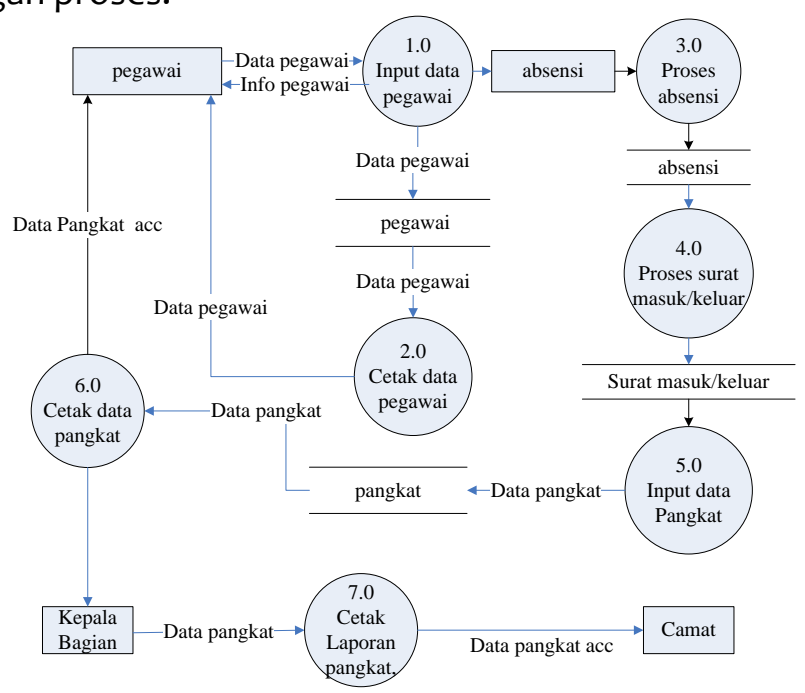

Gambar 2 Data Flow Diagram

Entity relationship diagram digunakan untuk menggambarkan relasi antar tabel dengan tujuan untuk memperjelas hubungan antar tabel penyimpanan. ERD terdiri dari sekumpulan objek dasar yaitu entitas dan hubungan antar entitas-entitas yang saling berhubungan. 


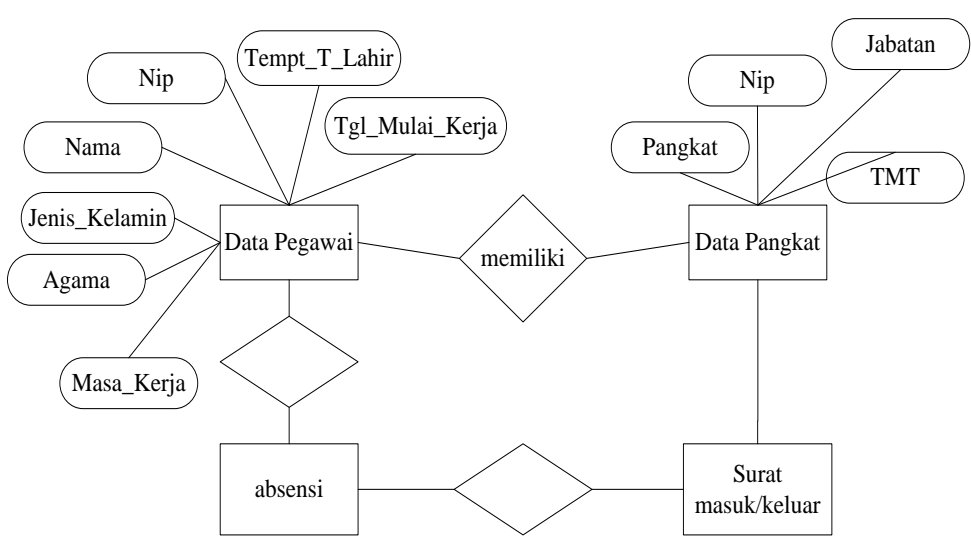

Gambar 3 Entity Relational Diagram(ERD)

Pada rancangan ini, flowchart menerangkan secara terperinci langkah-langkah dari proses program. Dengan menggunakan flowchart maka penjabaran dari rancangan modul akan lebih jelas. Berikut ini merupakan flowchart dari sistem informasi kepegawaian yang dirancang.

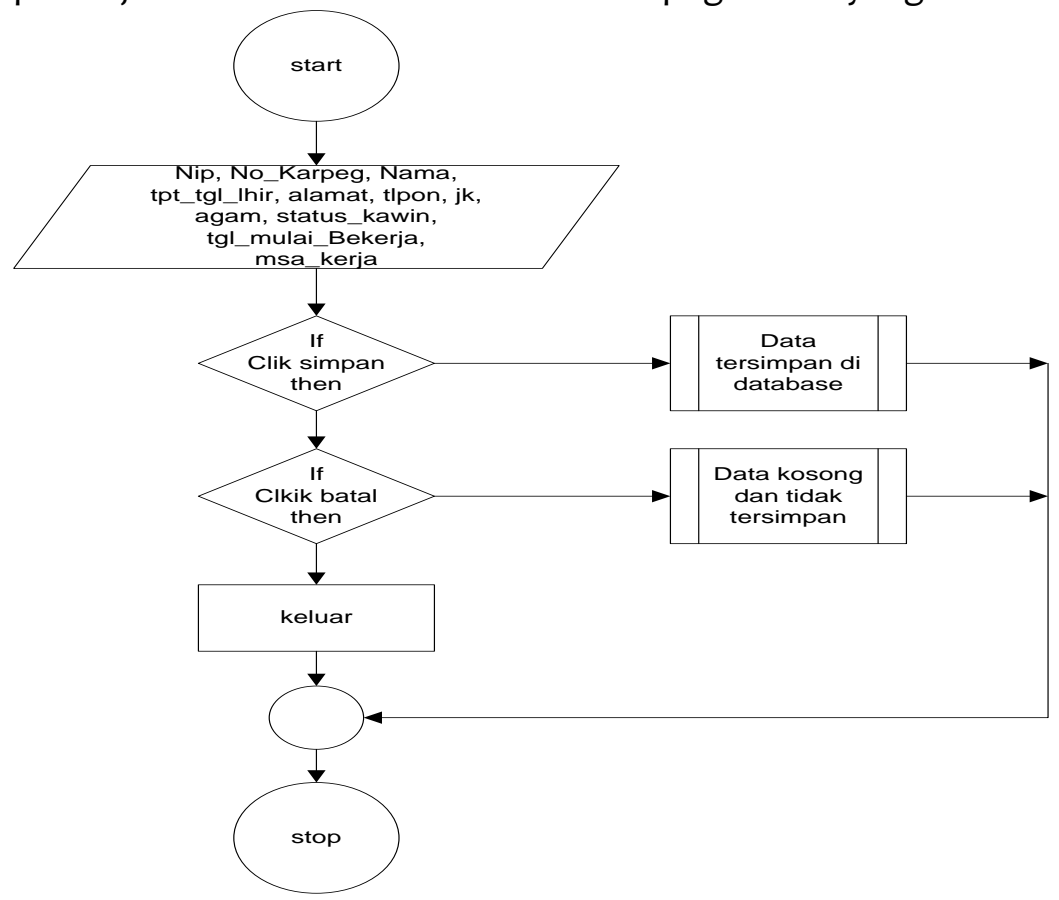

\section{Gambar 4 Flowchart Penjualan Perlengkapan Olahraga}

\section{IMPLEMENTASI SISTEM}

Sebelum sistem diterapkan dan di implementasikan, maka sistem tersebut harus jauh dari kesalahan-kesalahan penulisan bahasa, kesalahan sewaktu proses atau kesalahan dalam logika. Setelah sistem tersebut telah sesuai dan tidak ada kesalahan sistem tersebut di coba dengan membuka halaman-halaman yang ada.

Pengaksesan sistem ini dibedakan menjadi dua bagian yaitu bagian admin yang mempunyai hak akses penuh dalam mengelola isi website tersebut dan bagian pengguna untuk mengolah data sistem pakar pembagian harta waris.

Implementasi dilakukan agar setiap pengguna sistem dapat mengerti tentang bagaimana cara kerja sistem tersebut. Dibawah ini adalah beberapa implementasi dari sistem pakar pembagian harta waris.

Menu Index merupakan proses saat halaman tersebut dituju. Menu index disebut juga menu home karena merupakan proses awal saat masuk kedalam sistem/ program. 


\begin{tabular}{|l|l|}
\hline \hline Home $\quad$ Pegawai $\quad$ Pangkat Gelamat Datang di Web Site Pegawai \\
\hline \hline \\
\hline Website ini menampilkan Sistem Informasi Karyawan dimana terdapat menu seperti menu jabatan yaitu untuk menampilkan kode jabatan serta nama \\
jabatan, menu absensi untuk absen para pegawai dari absen pagi sama absen sore, menu karyawan merupakan data-data karyawan yang bekerja di Kantor \\
Camat Gaung Anak Serka (GAS) serta Surat Masuk dan Surat Keluar untuk memberitahukan jumlah Surat Masuk dan Keluar setiap bulannya.
\end{tabular}

\section{Gambar 5 halaman menu utama} absensi.

Tampilan Pada menu Utama ada data karyawan, data pangkat, pendidikan, data jabatan dan

1. Home, digunakan untuk menginfomasikan data program dan ucapan selamat datang kepada pengunjung. Menu home disebut juga menu index karena sistem diarahkan masuk ke menu tersebut saat program pertama kali dibuka.

2. Data Karyawan, digunakan untuk menginputkan biodata pegawai

3. Data Pangkat, digunakan untuk menginputkan informasi pangkat setiap pegawai.

4. Pendidikan, ini digunakan untuk menginput data pendidikan pegawai.

5. Data jabatan, digunakan untuk menginputkan jabatan setiap pegawai yang ada pada kantor camat gaung anak serka.

6. Absensi, digunakan untuk melihat kehadiran setiap pegawai kantor camat gaung anak serka. Menu data pegawai merupakan menu untuk menginput biodata pegawai yang ada di kantor camat gaung anak serka seperti ditunjukkan pada Gambar 6.

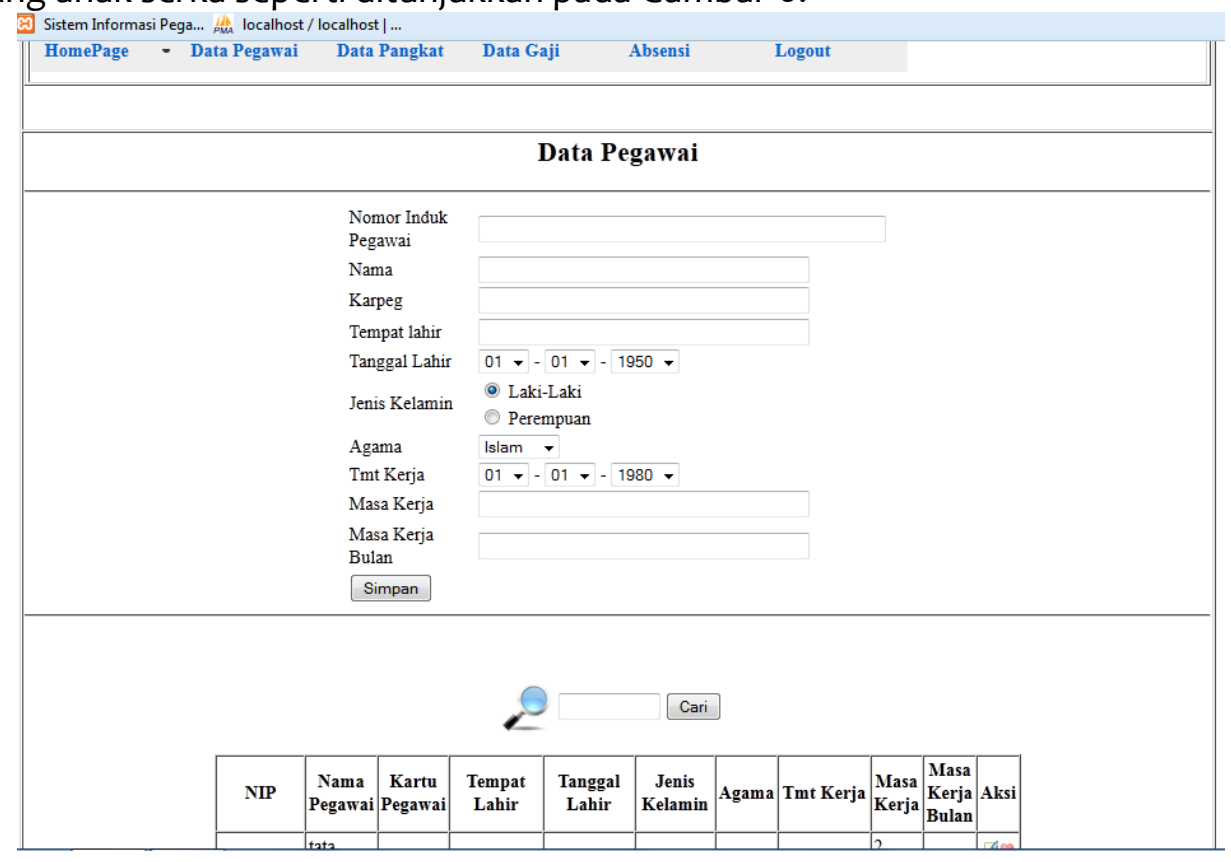

Gambar 6 Halaman Menu Data Pegawai 


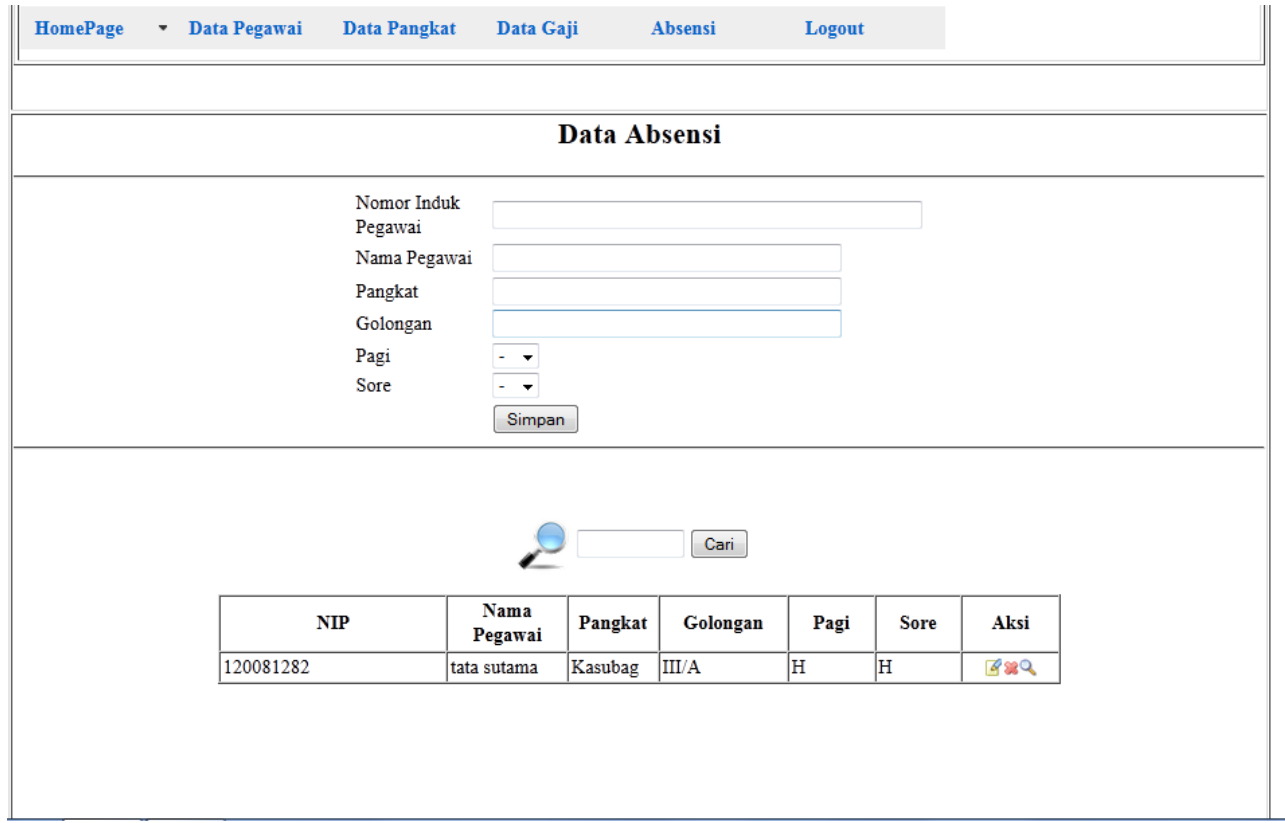

\section{Gamabr 7 Halaman Menu Absensi}

Langkah-lankah untuk menambah data absensi adalah sebagai berikut:

1. Input data absensi yang telah tersedia .

2. Kemudian data yang telah diisi dapat dilakukan proses simpan data absensi.

\section{KESIMPULAN}

Adapun kesimpulan yang dapat diambil oleh penulis dalam penyelesaian penelitian tugas akhir ini adalah sebagai berikut :

1. Dengan adanya sistem informasi pegawai berbasis web ini, maka akan mempermudah dalam melakukan pendataan pegawai dan dapat meminimalisir kesalahan yang terjadi dalam pengolahan data pegawai.

2. Dengan sistem informasi pegawai berbasis web ini pencarian data-data pegawai kantor camat akan lebih mudah.

3. Dengan sistem informasi pegawai laporan data pegawai pada kantor camat akan lebih efesien.

4. Pengolahan data pegawai menjadi terkomputerisasi dengan adanya sistem informasi pegawai berbasis web. berikut:

Adapun saran yang dapat dikembangkan untuk sistem data pegawai ini adalah sebagai

1. Program pengolahan data pegawai ini masih banyak terdapat kekurangan sehingga masih belum sempurna dalam penggunaannya, untuk itu diharapkan adanya pengembangan yang dilakukan untuk dapat lebih memperbaiki kekurangan yang terdapat pada program ini.

2. Untuk mendapatkan hasil yang maksimal maka disarankan pada pihak kantor camat gaung anak serka agar dapat melakukan pemeliharaan terhadap sistem secara berkala.

3. Dalam merancang sebuah program aplikasi sebaiknya menggunakan perangkat komputer yang mendukung dan sesuai dengan yang dibutuhkan oleh bahasa pemrograman itu sendiri agar lebih mudah dalam hal mengoperasikannya.

\section{REFERENSI}

Albahra,L. (2005), “Analisa dan Desain Sistem Informasi”, Edisi I, Graha Ilmu, Yogyakarta.

Hanif, A.F. (2007), "Analisa dan Perancangan Sistem Informasi”, Edisi I, Andi, Yogakarta.

Jogiyanto, H.M. (2005), “Analisa dan Desain”, Edisi III, Andi, Yogyakarta. 
Kristanto, A. (2008), “Perancanagan Sistem Informasi \& Aplikasi ”, Gava Media, Yogyakarta.

Kadir, A. (2008), “Dasar Prmograman Web Dinamis Menggunakan PHP”, Edisi III, Andi, Yogyakarta.

M, Rudyanto, A. (2011), “Prmograman Web Dinamis Menggunakan PHP \& MySQL”, Edisi I, Andi Yogyakarta. 